\title{
Increase of a Calcium Independent Transglutaminase Activity in the Erythrocyte during the Infection with Plasmodium falciparum
}

\author{
Moisés Wasserman/**/+, Ana Mercedes Márquez*, Mauricio Urquiza**, \\ Patricia Jiménez**
}

\author{
Grupo de Bioquímica, Instituto Nacional de Salud, Av. Eldorado Cra. 50, Apdo Aereo 80080, Bogotá, D.C., \\ Colombia *Facultad de Ciencias, Pontificia Universidad Javeriana, Bogotá, D.C., Colombia \\ **Facultad de Ciencias, Universidad Nacional de Colombia, Bogotá, D.C., Colombia
}

We have studied the activity of a calcium dependent transglutaminase (EC 2.3.2.13) during the growth of the parasite Plasmodium falciparum inside the infected human erythrocyte. There is only one detectable transglutaminase in the two-cell-system, and its origin is erythrocytic. No activity was detected in preparations of the parasite devoid of erythrocyte cytoplasm. The Michaelis Menten constants (Km) of the enzyme for the substrates N'N'dimethylcaseine and putrescine were undistinguishable whether the cell extracts used in their determination were obtained from normal or from infected red cells. The total activity of transglutaminase in stringently synchronized cultures, measured at $0.5 \mathrm{mM} \mathrm{Ca}{ }^{2+}$, decreased with the maturation of the parasite. However, a fraction which became irreversibly activated and independent of calcium concentration was detected. The proportion of this fraction grew with maturation; it represented only $20 \%$ of the activity in $20 \mathrm{hr}$-old-trophozoites while in 48-hr-schizonts it was more than $85 \%$ of the total activity. The activation of this fraction of transglutaminase did not depend on an increase in the erythrocyte cytoplasmic calcium, since most of the calcium was shown to be located in the parasite.

Key words: Plasmodium falciparum - malaria - erythrocyte - transglutaminase - calcium

Calcium plays important roles during the invasion and maturation of the parasite Plasmodium falciparum in the human erythrocyte. In a previous work Wasserman et al. (1982) showed that in the presence of EGTA the young trophozoites developed only for a few hours and then the cycle was irreversibly arrested. In other studies (Geary et al. 1986, Matsumoto et al. 1987, Scheibel et al. 1987, Tanabe et al. 1989) it has been reported that calmodulin antagonists and calcium blockers inhibit the growth of $P$. falciparum in red cells. Elsewhere we have reported an entrance of calcium in the erythrocyte during invasion (Wasserman et al. 1990). We have proposed that the transient rise of calcium concentration might act as a second mes-

\footnotetext{
This work was supported by the Instituto Colombiano para el Desarrollo de la Ciencia y la Tecnología "Francisco José de Caldas" Colciencias (project 2104-0417095 col. 044-96), by the Instituto Nacional de Salud de Colombia and by the Universidad Nacional de Colombia.

${ }^{+}$Corresponding author. Fax: +57-1-2220975. E-mail: mwasserm@colciencias.gov.co.

Received 30 April 1998

Accepted 26 October 1998
}

senger triggering a cascade of molecular events that render the red blood cell prone to invasion (Wasserman 1990). Several of these events have been shown to modify the cytoskeleton of the red blood cell (Wasserman et al. 1990). Other authors (Ginsburg et al. 1983, Krungkrai \& Yuthavong 1983, Kramer \& Ginsburg 1991) have shown changes in the permeability of the cell infected with mature parasites, changes that cause an increase in intracellular calcium concentration. Krogstad et al. (1991) confirmed the above described findings, and proposed that during infection a red blood cell calcium dependent transglutaminase was activated. The transglutaminase cross-links the cytoskeletal proteins, thus changing the normal shape and deformability of the red blood cell. A similar finding was reported when normal erythrocytes were treated with calcium and the calcium-ionophore A23187 (Kuettner et al. 1977, Lorand 1988). Krogstad's view was objected to (Clark 1991) because the concentration of calcium necessary to activate the transglutaminase is not likely to be reached, even transiently, during the infection of the red cell by Plasmodium.

In this paper we have examined the activity of transglutaminase (EC 2.3.2.13) during the erythrocytic cell cycle of $P$. falciparum. We were ca- 
pable of demonstrating that an activity of transglutaminase was present in the infected cell and that its origin was solely erythrocytic. As the cycle proceeded, a fraction of the enzyme became irreversibly activated and its proportion increased with the age of the parasite. We postulate that this enzyme could be activated by other calcium dependent enzymes, i.e. proteases that need only micromolar calcium concentrations to become fully active.

\section{MATERIALS AND METHODS}

Cell culture - The parasites - Colombian FCB2 strain of $P$. falciparum - were continuously maintained in human $\mathrm{O}+$ erythrocytes (Trager \& Jensen 1976) in a $90 \% \mathrm{~N}_{2}, 5 \% \mathrm{O}_{2}$ and $5 \% \mathrm{CO}_{2}$ atmosphere (Incubator Tabai BN210). The medium used was RPMI-1640 (Sigma) supplemented with 0.2 $\mathrm{mM}$ hypoxanthine, $1 \mathrm{mg} / \mathrm{ml}$ reduced glutathione, $25 \mathrm{mM}$ HEPES, $10 \%$ human serum and $50 \mathrm{mg} / \mathrm{ml}$ gentamycin. Human erythrocytes were freed from leukocytes by centrifugation through Ficoll-paque (Pharmacia) cushions. The parasite culture was synchronized by $5 \%$ sorbitol induced lysis of mature forms (Lambros \& Vanderberg 1979). When the culture reached the stage of mature schizonts, the parasites were concentrated by percoll gradient centrifugation (Rivadeneira et al. 1983). A preparation containing almost $90 \%$ schizonts was diluted with fresh erythrocytes and invasion was allowed to proceed for $12 \mathrm{hr}$ at a hematocrit of 0.5 to $1 \%$ (Vernot \& Wasserman 1990). The highly parasitized culture was concentrated to a $5 \%$ hematocrit and samples were obtained at the desired developmental stages.

The samples containing mature trophozoites and schizonts were concentrated with percoll gradients as described before. Samples containing rings were concentrated with a combined sorbitolpercoll gradient as described (Kutner et al. 1985). The cell density in all samples was quantified by hematocytometry using a Neubauer chamber and the parasitemia was evaluated on Giemsa stained smears, counting 10,000 cells. The differential lysis of the cells was done by incubation at $37^{\circ} \mathrm{C}$ for $5 \mathrm{~min}$ in an isotonic solution containing $0.15 \%$ saponine. Sediment of residual membranes and parasites was removed by a 10 min-centrifugation at $15,000 \mathrm{x} \mathrm{g}$ (Eppendorff centrifuge).

Quantification of calcium - Total calcium was quantified using atomic absorption spectrophotometry in a graphite oven. Polyethylene and polymethylpentene labware was used in the determination. The plasticware was soaked in a solution of $30 \% \mathrm{HNO}_{3}$ for $3 \mathrm{hr}$, and rinsed with boiling deionized water (Type RI). The saponine and $\mathrm{HCl}$ solutions were deionized using $1 \mathrm{~g}$ of resin AG-
501-X8 (BioRad) per $100 \mathrm{ml}$ solution. Other buffers and solutions were equally treated but with the resin Chelex-100 (BioRad) in its sodium form. To avoid phosphate interferences the samples were mixed with $0.5 \mathrm{M} \mathrm{HCl}$ and $4 \mathrm{mM} \mathrm{LaCl}_{3}$. The determinations were performed in a Perkin Elmer 2380 Atomic Absorption Spectrophotometer equipped with a graphite oven (HGA400). The following protocol was used: drying at $100^{\circ} \mathrm{C}$ for $10 \mathrm{sec}$, calcination at $1,000^{\circ} \mathrm{C}$ for $5 \mathrm{sec}$ and atomization at $2,400^{\circ} \mathrm{C}$ for $5 \mathrm{sec}$. The reading was done at the last stage. The transporter gas was Argon of high purity at a flow of $50 \mathrm{ml} / \mathrm{min}$. A calibration curve between 0.1 and $0.5 \mathrm{mM}$ was constructed with a $\mathrm{CaCl}_{2}$ standard.

Transglutaminase assay - The activity of transglutaminase was measured as described by Lorand et al. (1978) and Takagi et al. (1986) with slight modifications as follows: samples of $30 \mathrm{ml}$ of the different extracts containing also $2 \mathrm{mg} / \mathrm{ml}$ dimethylcaseine and $5 \mathrm{mCi}$ of ${ }^{3} \mathrm{H}$-putrescine (5-40 $\mathrm{Ci} / \mathrm{mmol}$ ) were incubated in Eppendorff tubes with continuous agitation at $37^{\circ} \mathrm{C}$ for $1 \mathrm{hr}$. Three different conditions were routinely used: the first was in the presence of $0.5 \mathrm{mM} \mathrm{CaCl}$ for determination of total potential activity, the second without addition of calcium for determination of the actual activity and the third one with the addition of $1 \mathrm{mM}$ EGTA for the determination of the calcium-independent irreversibly activated fraction of the enzyme.

The reaction was stopped by the addition of 1 $\mathrm{ml}$ ammonium sulphate (80\% sat.). After complete precipitation of the casein, the tubes were centrifuged at $15,000 \mathrm{x}$ g for $5 \mathrm{~min}$. The supernatant was discarded and the pellet was resuspended and washed three times with the same solution. After the last wash, the pellet was drained and solubilized in $0.1 \mathrm{ml}$ of a HEPES buffered isotonic solution. The whole sample was mixed with $3 \mathrm{ml}$ of a scintillation cocktail for aqueous samples (ReadySolv Beckman) and radioactivity was determined in a scintillation counter. Samples were processed in triplicate.

The determination of the Michaelis-Menten constants was performed with cell extracts diluted ten times with HEPES buffered isotonic solution and in the presence of $0.5 \mathrm{mM} \mathrm{Ca}^{2+}$. The concentration of putrescine varied between $0.2 \times 10^{-6}$ and $8 \times 10^{-6} \mathrm{M}$ and that of N'N'Dimethylcaseine between $0.5 \times 10^{-7}$ and $8 \times 10^{-7} \mathrm{M}$. The activity was measured as described before, and the rates were expressed as D:P:M. of ${ }^{3} \mathrm{H}$ incorporated per minute in N'N' dimethyl-caseine.

\section{RESULTS}

Transglutaminase activity in infected erythrocytes - A calcium dependent transglutaminase ac- 
tivity is observed in erythrocytes infected with the parasite P. falciparum. However, the activity of the parasitized cell is undistinguishable from that of the uninfected erythrocyte. We show in Fig. 1 that the total activity in a cell infected with a young trophozoite (about $12 \mathrm{hr}$-old), measured in the presence of calcium, is only slightly lower than that in a normal erythrocyte. The transglutaminase activity is located mainly in the cytoplasm. The sediments of uninfected membranes and of membranes plus parasites are virtually free of transglutaminase whether the activity is measured in the presence or in the absence of calcium.

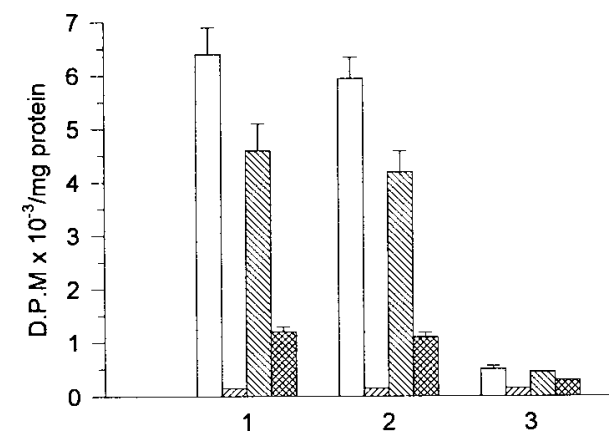

Fig.1: localization of transglutaminase activity in normal and infected cells. Whole cell extracts (1), cytoplasmic extracts (2) and sediments of saponine treated cells (3) were used to quantify the transglutaminase activity. The first and second bars of each group correspond to normal uninfected cells assayed in the presence (first bar) and absence (second bar) of calcium. The third and fourth bars of each group correspond to $12 \mathrm{hr}-$ old-trophozoite infected cells in the presence (third bar) and absence (fourth bar) of calcium.

The Michaelis Menten constants of the enzyme were calculated for both substrates $\left({ }^{3} \mathrm{H}\right.$-putrescine and N'N'dimethyl-casein), in extracts of uninfected and infected erythrocytes (Fig. 2). The results obtained were $0.48 \times 10^{-6} \mathrm{M}$ for putrescine and 0.53 $\mathrm{x} 10^{-7} \mathrm{M}$ for N'N'dimethylcaseine, and were the same for the infected and for the uninfected cell extracts. This fact supports the observation that there is only one calcium dependent transglutaminase in the two cell system and that it comes from the erythrocyte.

We also show in Fig. 1 that the basal activity is very low, since it is barely noticeable without the addition of $\mathrm{Ca}^{2+}$ to a concentration of $0.5 \mathrm{mM}$. However, in the absence of calcium the activity is consistently higher in the cytoplasm of the infected erythrocyte. This fact can be related either to a permanent activation or to a higher endogenous calcium concentration in the infected erythrocyte cytoplasm. Fig. 3 suggests that the latter is not the case. The total calcium concentration was measured
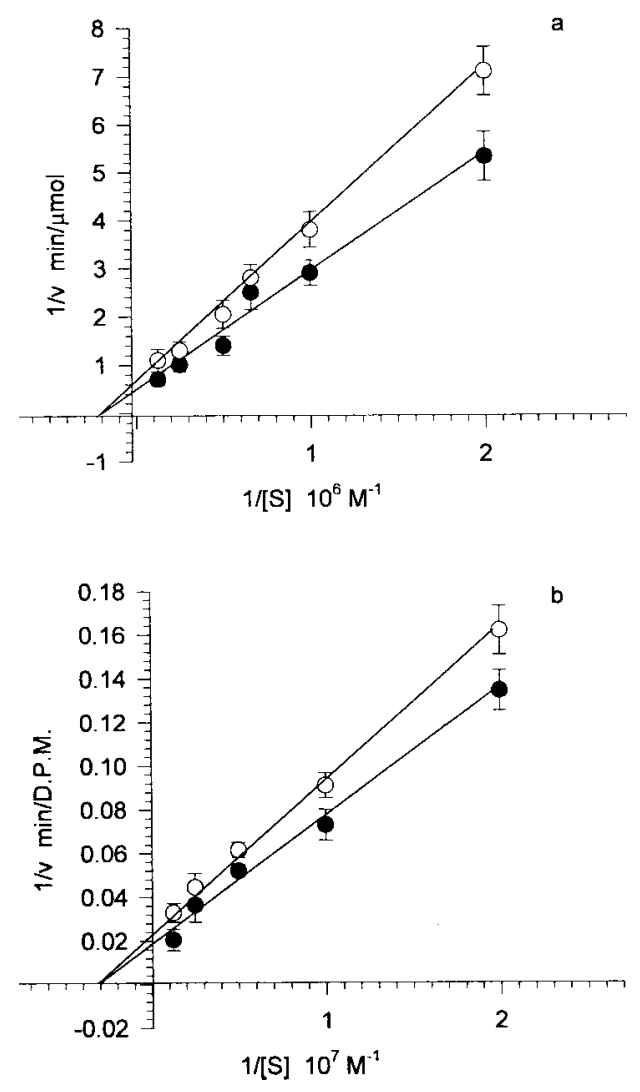

Fig. 2: Michaelis-Menten constants of the transglutaminase from normal and infected cells. Lineweaver-Burk plots were drawn for uninfected $(\mathrm{TM})$ and infected $(-)$ cell extracts. The $\mathrm{Km}$ were calculated as the negative reciprocal of the $1 /[\mathrm{S}]$ value when $1 / \mathrm{v}$ equals zero for both putrescine (a) and N'N'dimethylcaseine (b).

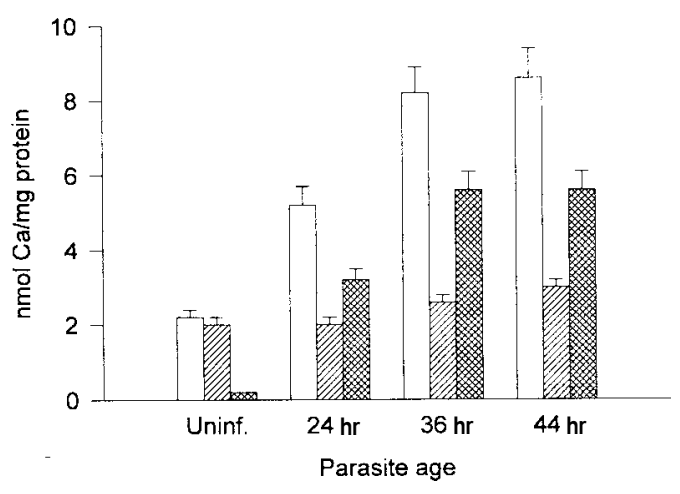

Fig. 3: total calcium contents in the parasitized cell. Samples of normal and parasitized cells (concentrated as described) were fractionated in cytoplasm and sediment of residual membranes and parasites. Total calcium was determined by atomic absorption spectrophotometry with a graphite oven. The results for whole cells (white bars), cytoplasm (diagonally striped bars) and parasites (hatched bars) are shown for uninfected erythrocytes and for three synchronized cultures at different ages. 
by atomic absorption with a graphite oven. When evaluating the cytoplasm extract prepared with saponine - which leaves the parasite undisrupted we observed that the total calcium in the infected cell increases steadily with maturation. However, this increase was mainly due to calcium located in the undisrupted parasite and not in the erythrocyte cytoplasm. The total calcium in the cytoplasm increased by no more than $30 \%$ while that retained in the saponine pellet was 30-50 times higher in mature trophozoites and schizonts than in uninfected cells. Nevertheless, in order to avoid ambiguities, the experiments presented in Fig. 4 were done with saponine extracts in which the erythrocyte cytoplasm was diluted only by a factor of 1.2.

Changes in the transglutaminase activity throughout the erythrocytic cell cycle - Synchronous cultures were obtained as described, and the activity of the cytoplasmic extract was measured in the presence of $0.5 \mathrm{mM} \mathrm{Ca}^{2+}$ without the addition of $\mathrm{Ca}^{2+}$, and with EGTA $1 \mathrm{mM}$ to ensure a
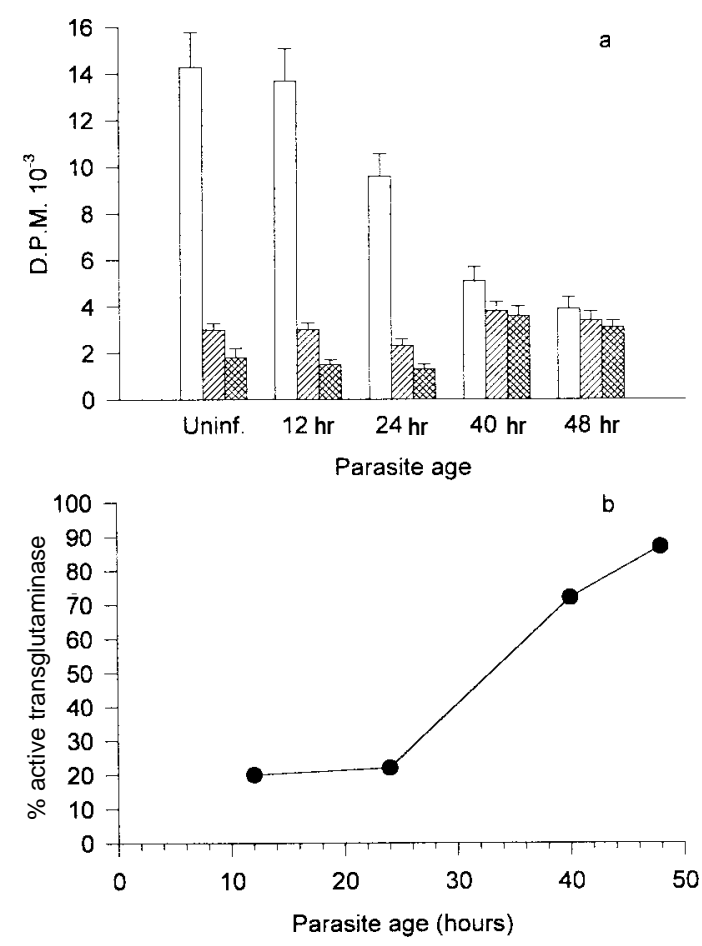

Fig. 4: activity of transglutaminase through the erythrocytic cycle of the parasite. The activity of the transglutaminase was expressed as D.P.M. of incorporated ${ }^{3} \mathrm{H}$-putrescine to N'N'dimethylcaseine (a). The total activity in the presence of $0.5 \mathrm{mM} \mathrm{Ca}^{2+}$ (white bars), the activity of the extract without additions (diagonally striped bars) and the activity in the presence of 1 mM EGTA (hatched bars) were quantified. The proportion of transglutaminase that becomes independent of $\mathrm{Ca}^{2+}$ is shown as a percentage of the total activity (b). submicromolar concentration of calcium (as in the normal cell). Fig. 4a shows that the total transglutaminase activity in the presence of $\mathrm{Ca}^{2+}$ decreases steadily with the parasite maturation, probably due to the digestion of erythrocyte cytoplasm by the parasite. However, there is a fraction of transglutaminase that seems to become unsensitive to calcium and irreversibly activated. This fraction increases proportionally with age, and in $48 \mathrm{hr}$-old schizonts it is almost $90 \%$ of all the detectable activity (Fig. 4b). It strongly contrasts with the $12 \mathrm{hr}$-old rings in which the irreversibly active fraction is barely $20 \%$ of the total.

Effect of transglutaminase inhibitors in the development of the parasite - When present in the medium at a $2 \mathrm{mM}$ concentration for $15 \mathrm{hr}$, putrescine, a competitive inhibitor of transglutaminase, inhibited the invasion to $50 \%$. This experimental system does not differentiate if the inhibition occurs at the last stages of maturation, at liberation, or at invasion. Cystamine $1 \mathrm{mM}$, reported to be an irreversible inhibitor of transglutaminase (Siefring et al. 1978), was added to a synchronous culture of $P$. falciparum at 12, 24, 36 and $48 \mathrm{hr}$. Although the effects were not very strong, a delay in development was noticed when cystamine was added at 12 or $24 \mathrm{hr}$. The final steps of maturation were seriously delayed and the parasites were extensively vacuolated. When the cystamine was added to $48 \mathrm{hr}$-old schizonts the invasion was diminished to a $30 \%$ of the control.

\section{DISCUSSION}

The changes in shape and membrane fluidity suffered by erythrocytes infected with P. falciparum (Krogstad et al. 1991) are reminiscent of those produced in normal erythrocyte by an induced entrance of calcium (Kuettner et al. 1977, Kon et al. 1993). This fact suggests the involvement of a transglutaminase activity, which causes extensive crosslinking of the cytoskeletal proteins during the maturation of the parasite. Moreover, a crosslinked form of band 3 has been shown to be an important antigen, probably related to the cytoadherence, in the mature parasite (Winograd \& Sherman 1989).

We have previously shown that there is a calcium entrance in the erythrocyte during the invasion (Wasserman et al. 1990), and suggested that a localized higher cytoplasmic calcium concentration might be a second messenger triggering a series of molecular events that render the erythrocyte prone to invasion (Wasserman 1990). Krogstad et al. (1991) have re-examined the role of calcium in the maturation of the intraerythrocytic $P$. falciparum. They suggest that the loss of red cell deformability, and the alterations in the cytoskeletal proteins of the parasitized cells might 
be due to a parasite-induced change in the calcium permeability of the cell and the consequent activation of endogenous transglutaminases in the red cell cytoplasm. However, Clark (1991) has objected to their view, mainly based on the fact that transglutaminase mediated crosslinking is detectable in erythrocytes only when $\mathrm{Ca}^{2+}$ concentrations are superior to $300 \mathrm{mM}$. This situation is very unlikely to occur, as it is probably incompatible with the $48 \mathrm{hr}$-life term of the parasitized erythrocyte.

In this paper we present experimental evidence about the involvement of a transglutaminase in the process of maturation. We have defined this transglutaminase as erythrocytic and we have shown that it is sensitive to calcium. Our results seem to favor a gradual irreversible activation through the maturation process rather than the activation caused by a permanent increase of the cytosolic calcium. Moreover, when quantifying total calcium, we have shown that most of it was located in a compartment resistant to saponine treatment, in other words, that it was concentrated inside the parasite. The erythrocytic cytoplasm content of calcium was barely increased by a $30 \%$ over that of non infected cells (Fig. 3). A similar result was reported for cytosolic free calcium using a cytofluorometric method (Adovelande et al. 1993). The fraction of transglutaminase that seemed to be constitutively activated in the infected erythrocyte increased. It became significantly higher when the cellular deformations and changes in membrane rigidity at trophozoite stage appeared. Late in schizogony it became the predominant transglutaminase fraction (Fig. 4).

The only transglutaminase that was detectable in this system originated in the erythrocyte. Although the assay is very sensitive, it was not possible to detect a significant activity in parasites free of erythrocyte cytoplasm (Fig. 1). Moreover, the Michaelis-Menten constants of the enzyme for both substrates were the same for infected and for uninfected cell extracts (Fig. 2). These results strongly suggest that there is indeed only one transglutaminase in the infected cell. This might be an example of subversion - for the purposes of the parasite - of the erythrocytic enzyme machinery.

If the activation of the transglutaminase is not directly caused by an increase in calcium concentration, the mechanism of the activation remains an open question. One possibility is that the crosslinking activity detected here and previously suggested by Krogstad corresponds to a reported membrane-associated erythrocyte transglutaminase (Billet \& Puszkin 1991) which is activated by calmodulin and calcium at micromolar concentrations. However, our results seem to contrast with this option. A second possibility is that the reported activity could be a colateral effect of the transient calcium rise during invasion. This rise could activate other calcium dependent enzymes as the proteinase calpain, which becomes irreversibly activated at micromolar calcium concentrations and might activate transglutaminase (Chung et al. 1988). Calpain has been shown also to be involved in the invasion of the erythrocyte by Plasmodium (Olaya \& Wasserman 1991).

The role of transglutamination during infection is not clear. It does not seem at first sight advantageous for the parasite to enhance the fragility of its host cell. However, some of the products of transglutamination could be involved in the sequestration of the mature trophozoite in the capillary vessels (Winograd \& Sherman 1989). Moreover, the rigidity of the cell and the changes in its shape could be related to the final disruption for the liberation of the merozoites. The resemblance of the effect reported here to the apoptosis of other cells is intriguing. It is tempting to propose that, while invading the erythrocyte, the parasite commits it to die in $48 \mathrm{hr}$, or at least, to change deeply its structure simultaneously with the completion of the cycle. The liberation of the newly formed merozoites would be thus greatly facilitated by this degenerative process.

\section{REFERENCES}

Adovelande J, Bastide B, Deleze J, Schrevel J 1993. Cytosolic free calcium in Plasmodium falciparuminfected erythrocytes and the effect of Verapamil A cytofluorimetric study. Exp Parasitol 76: 247-258.

Billet HH, Puszkin EG 1991. The red cell membrane contains calmodulin-regulated crosslinking and proteolytic activity. Hematol Pathol 5: 185-193.

Chung SI, Chang SK, Cocuzzi ET, Folk JE, Kim HC, Lee SY, Martinet N, Nigra T, Sun HS 1988. Modulation of cellular transglutaminase: protease-induced activation. Adv Exp Med Biol 231: 1-13.

Clark MR 1991. Calcium and the malaria parasite - Parasite maturation and the loss of red cell deformability - Commentary. Blood Cells 17: 242-245.

Geary TG, Divo AA, Jensen JB 1986. Effect of calmodulin inhibitors on viability and mitochondrial potential of Plasmodium falciparum in culture. Antimicrob Agents Chemother 30: 785-788.

Ginsburg H, Krugliak M, Eidelman O, Cabantchik ZI 1983. New permeability pathways induced in membranes of Plasmodium falciparum infected erythrocytes. Mol Biochem Parasitol 8: 177-190.

Kon K, Murakami J, Maeda N, Shiga T 1993. Effect of intracellular calcium content on erythrocyte deformation. Biomed Res 14: 131-133.

Kramer R, Ginsburg H 1991. Calcium transport and compartment analysis of free and exchangeable calcium in Plasmodium falciparum-infected red blood cells. J Protozool 38: 594-601.

Krogstad DJ, Sutera SP, Marvel JS, Gluzman IY, Boylan CW, Colca JR, Williamson JR, Schlesinger PH 1991. 
Calcium and the malaria parasite - Parasite maturation and the loss of red cell deformability. Blood Cells 17: 229-241.

Krungkrai J, Yuthavong Y 1983. Enhanced $\mathrm{Ca}^{2+}$ uptake by mouse erythrocytes in malarial (Plasmodium berghei) infection. Mol Biochem Parasitol 7: 227235 .

Kuettner JF, Dregher KL, Gundu BS, Rao HR, Eaton JW, Blackshear PL, White JG 1977. Influence of the ionophore A23187 on the plastic behavior of normal eythrocytes. Am J Pathol 88: 81-94.

Kutner S, Breuer WV, Ginsburg H, Aley SB, Cabantchik ZI 1985. Characterization of permeation pathways in the plasma membrane of human erythrocytes infected with early stages of Plasmodium falciparum: association with parasite development. J Cell Physiol 125: 521-527.

Lambros C, Vanderberg J 1979. Synchronization of the Plasmodium falciparum erythrocytic stages in culture. J Parasitol 65: 418-420.

Lorand L 1988. Transglutaminase-mediated cross linking of protein and cell ageing: The erythrocyte and lens model. Adv Exp Med 231: 79-94.

Lorand L, Siefring GE, Lowe-Krentz L 1978. Formation of g-Glutamil-eLysine bridges between membrane proteins by a $\mathrm{Ca}^{2+}$-regulated enzyme in intact erythrocytes. J Supramol Structure 9: 427-440.

Matsumoto Y, Perry G, Scheibel LW, Aikawa M 1987. Role of calmodulin in Plasmodium falciparum: implications for erythrocyte invasion by the merozoite. Eur J Cell Biol 45: 36-43.

Olaya P, Wasserman M 1991. Effect of calpain inhibitors on the invasion of human erythrocytes by the parasite Plasmodium falciparum. Biochim Biophys Acta 1096: 217-221.

Rivadeneira E, Wasserman M, Espinal C 1983. Separation and concentration of schizonts of Plasmodium falciparum by percoll gradients. J Protozool 30: 367 -
370.

Scheibel LW, Colombani PM, Hess AD, Aikawa M, Atkinson CT, Milhous WK 1987. Calcium and calmodulin antagonists inhibit human malaria parasites (Plasmodium falciparum): Implications for drug design. Proc Natl Acad Sci USA 84: 7310-7314.

Siefring GE, Apostol AB, Velasco PT, Lorand L 1978. Enzymatic basis for the Ca++-induced cross-linking of membrane proteins in intact human erythrocytes. Biochemistry 17: 2598-2604.

Takagi J, Saito Y, Kikuchi T, Inada Y 1986. Modification of transglutaminase assay: use of ammonium sulphate to stop the reaction. Anal Biochem 153: 295 298.

Tanabe K, Isumo A, Kato M, Miki A, Doi S 1989. Stagedependent inhibition of Plasmodium falciparum by potent $\mathrm{Ca}^{2+}$ and calmodulin modulators. J Protozool 36: 139-143.

Trager W, Jensen J 1976. Human malaria parasite in continuous culture. Science 193: 673-675.

Vernot JP, Wasserman M 1990. Plasmodium falciparum: Increased and multiple invasion during short periods of time. J Protozool 37: 47-49.

Wasserman M 1990. Commentary: The role of calcium ions in the invasion of Plasmodium falciparum. Blood Cells 16: 450-451.

Wasserman M, Alarcon C, Mendoza PM 1982. Effects of $\mathrm{Ca}^{2+}$ on the asexual cell cycle of Plasmodium falciparum. Am J Trop Med Hyg 31: 711-717.

Wasserman M, Vernot JP, Mendoza PM 1990. Role of calcium and erythrocyte cytoskeleton phosphorylation in the invasion of Plasmodium falciparum. Parasitol Res 76: 681-688.

Winograd E, Sherman IW 1989. Characterization of a modified red cell membrane protein expressed on erythrocytes infected with the human malaria parasite Plasmodium falciparum: Possible role as a cytoadherent mediating protein. J Cell Biol 108: 23-30. 